\title{
Effects of iodine-131 radiotherapy on Th17/Tc17 and Treg/Th17 cells of patients with differentiated thyroid carcinoma
}

\author{
LIXIA ZHANG, JINYAN CHEN, CAIYUN XU, LILI QI and YAN REN
}

Department of Nuclear Medicine, Zhejiang Provincial Hospital of Traditional Chinese Medicine, The First Affiliated Hospital of Zhejiang Chinese Medical University, Hangzhou, Zhejiang 310006, P.R. China

Received August 21, 2017; Accepted November 9, 2017

DOI: 10.3892/etm.2017.5663

\begin{abstract}
T helper 17 (Th17), T cytotoxic 17 (Tc17) and regulatory $\mathrm{T}$ (Treg) cells serve important roles in a number of inflammatory and autoimmune diseases. The aim of the present study was to examine the distribution of Th17, Tc17 and Treg cells in patients with differentiated thyroid cancer (DTC) prior to as well as 7, 30 and 90 days following radioactive iodine-131 ( $\left.{ }^{131} \mathrm{I}\right)$ therapy, and to elucidate the probable effects of ${ }^{131}$ I therapy on Th17/Tc17 and Treg/Th17 cells in patients with DTC. A total of 40 patients with DTC (26 female; 14 male) between the ages of 24 and 72 years, as well as 13 age- and sex-matched healthy subjects were included in this study. The number of Th17, Tc17 and Treg cells in the peripheral blood of patients with DTC and of healthy Controls were assessed by flow cytometry. Th17 and Tc17 cells were counted as percentages of the number of $\mathrm{CD}^{+} \mathrm{T}$ cells; Treg cells were counted as a percentage of the number of $\mathrm{CD}^{+} \mathrm{T}$ cells. In addition, the serum levels of interleukin (IL)-17, IL-23, IL-10 and transforming growth factor (TGF)- $\beta 1$ were examined by ELISA. The frequencies of Th17, Tc17 and Treg cells, as well as the serum levels of IL-17, IL-23, IL-10 and TGF- $\beta 1$ were significantly elevated in patients with DTC compared with healthy Controls, whereas ${ }^{131}$ I therapy significantly decreased them. In addition, elevated Th17/Tc17 ratio and reduced Treg/Th17 ratio were observed in patients with DTC at day 0, however, these ratios returned to normal levels following ${ }^{131}$ I therapy for 90 days as compared with healthy Controls. Notably, Th17/Tc17 and Treg/Th17 ratios varied following ${ }^{131}$ I therapy for 7 and 30 days. In addition, a strong positive correlation between Th17 and Tc17 cells was observed in the healthy Controls and patients with DTC that
\end{abstract}

Correspondence to: Dr Lixia Zhang, Department of Nuclear Medicine, Zhejiang Provincial Hospital of Traditional Chinese Medicine, The First Affiliated Hospital of Zhejiang Chinese Medical University, 54 Youdian Road, Hangzhou, Zhejiang 310006, P.R. China

E-mail:1ixiazh@yeah.net

Key words: differentiated thyroid cancer, $\mathrm{T}$ helper 17 cells, $\mathrm{T}$ cytotoxic 17 , regulatory $\mathrm{T}$ cells, radioactive iodine-131 received ${ }^{131}$ I treatment for 90 days, whereas a weak positive correlation between Th17 and Treg cell levels was identified in the healthy Controls and no obvious correlation between Th17 and Treg cells was observed in all patients with DTC pre- and post- ${ }^{131}$ I therapy during the entire treatment period. These data suggested a significant involvement of Th17, Tc17 and Treg cells in the pathology of DTC. Restoring the balance of these cells may contribute to the recovery of patients with DTC following ${ }^{131}$ I therapy.

\section{Introduction}

The incidence rate of thyroid tumor has increased over the past 30 years and tends to affect the young (1-3). Although thyroid carcinoma is rare and accounts for approximately $1 \%$ among human malignancies, it is the most common malignancy of the endocrine system $(4,5)$. Among thyroid malignancies, differentiated thyroid cancer (DTC) comprises the vast majority, $\sim 90 \%$, and includes papillary and follicular histological types (6). DTC cells have the ability to concentrate iodine and to synthesize and release thyroid hormones. This characteristic enables the administration of radioactive iodine-131 $\left({ }^{131} \mathrm{I}\right)$ to treat metastatic diseases and to ablate remnant thyroid tissues following thyroidectomy (7). In accordance with the European Association of Nuclear Medicine guidelines, certain patients with DTC are required to receive ${ }^{131}$ I therapy after surgery (8).

Immunological mechanisms are vital in the surveillance of malignancy and the control of cancer progression. Immune responses against DTC have long been recognized. T cells are crucial participants in the immune response. Previous studies have revealed that the imbalance between $\mathrm{T}$ helper (Th) 1 and Th2 cells is a major immunological mechanism in the pathogenesis of DTC (9-11). Three novel T cell subgroups, including Th17 cells $\left[\mathrm{CD}^{+} /\right.$interleukin (IL) $\left.17^{+} \mathrm{T}\right]$ cells, cytotoxic $\mathrm{T}\left(\mathrm{Tc} 17\right.$; $\left.\mathrm{CD}^{+} \mathrm{IL}_{17}{ }^{+} \mathrm{T}\right)$ cells and regulatory $\mathrm{T}$ (Treg; $\mathrm{CD} 4^{+} \mathrm{CD} 25^{+} \mathrm{Foxp}^{+} \mathrm{T}$ ) cells have gained increasing attention, as they may serve key roles in the development of infections, allergic reactions, autoimmune diseases and tumorigenesis $(12,13)$. Th17 cells exhibit the characteristics of CD4 ${ }^{+}$ T cells and secrete ILs, including IL-17, IL-21 and IL-22. Differentiation of Th17 cells occurs in the presence of IL-6, IL-21 and tumor growth factor (TGF)- $\beta$, and their stability is sustained by IL-1 $\beta$ and IL-23 $(14,15)$. Similar to Th17 cells, 
Tc17 cells are characterized by the production of IL-17. Tc17 cells have been implicated in immune-associated diseases and carcinomas $(16,17)$. Treg cells secrete TGF- $\beta$ and IL-10. The release of IL-10 aids Treg cells to greatly repress host immune responses, mainly by contributing to impaired antitumorimmunity in cancer-bearing subjects (18). In previous reports, the reciprocal relationships between Th17 and either Tc17 or Treg cell numbers in tumors have been emphasized. The imbalance between Th17 and Tc17 or Treg cells has been observed in several types of tumor, such as gastric (19), ovarian (20) and prostate cancer (21). In particular, recent studies have revealed that Th17, Tc17 and Treg cell levels are also abnormal in patients with DTC $(11,15,19,22)$; however, the specific relationships between Th17 cells and Tc17 or Treg cells, as well as the related cytokine secretion, remain unclear. ${ }^{131} \mathrm{I}$ treatment may have an effect on the hematopoietic system of patients with DTC, particularly on the lymphocytes; however, there little is known about $\mathrm{T}$ cells in patients with DTC patients following ${ }^{131}$ I treatment. Therefore, the present study aimed to investigate the effects of ${ }^{131} \mathrm{I}$ on the immune cell subsets, Th17, Tc17 and Treg cells, and the related cytokine production in patients with DTC.

\section{Materials and methods}

Patients. The study population included 40 patients with DTC (26 female; 14 male; age, 24-72 years); patient characteristics are provided in Table I. Among them, 29 (72.5\%) had papillary carcinomas and $11(27.5 \%)$ had follicular carcinomas. None of the patients had autoimmune diseases, chronic inflammation, allergic disease or other conditions that may affect the tested parameters. All patients with DTC underwent total thyroidectomy. At 4-6 weeks following surgery, patients received a low-iodine diet ( $<50 \mu \mathrm{g} /$ day) for $1-2$ weeks and subsequently were treated with a single dose of $3.7 \mathrm{GBq}(100 \mathrm{mCi})$ of ${ }^{131} \mathrm{I}$ (Chengdu Gaotong Isotope Cooperation, Chengdu, China) administered orally according to the EANM guidelines $(8,12)$. The Control group comprised 13 age- and sex-matched healthy subjects. This study protocol was approved by the Ethics Committee of The First Affiliated Hospital of Zhejiang Chinese Medical University (Hangzhou, China). All patients and Control subjects provided informed written consent prior to enrollment in the study.

Peripheral blood mononuclear cells (PBMCs) and serum preparation. Peripheral blood samples $(5 \mathrm{ml})$ from the study subjects were collected in EDTA tubes following venipuncture. Blood $(5 \mathrm{ml})$ was collected from Control subjects only once, whereas samples were collected from patients with DTC at day 0 , as well as 7, 30 and 90 days following ${ }^{131}$ I treatment. The blood $(0.5 \mathrm{ml}$ per subject) was combined with RPMI-1640 medium (5 ml; Sigma-Aldrich; Merck KGaA, Darmstadt, Germany) containing 10\% fetal bovine serum (FBS, Sigma-Aldrich; Merck KGaA), 2 mM glutamine, $100 \mathrm{U} / \mathrm{ml}$ penicillin and $100 \mathrm{U} / \mathrm{ml}$ streptomycin and incubated at $37^{\circ} \mathrm{C}$ for $72 \mathrm{~h}$. The supernatant was harvested by centrifugation at $1,400 \mathrm{x} \mathrm{g}$ for $12 \mathrm{~min}$ at room temperature and stored at $-20^{\circ} \mathrm{C}$ until required (11). Serum for the detection of cytokine levels was obtained by centrifugation at $2,000 \mathrm{x}$ g for $15 \mathrm{~min}$ at $4^{\circ} \mathrm{C}$ and stored at $-80^{\circ} \mathrm{C}$.
Table I. Clinicopathological characteristics of the 40 patients with differentiated thyroid cancer.

\begin{tabular}{llr}
\hline Characteristic & \multicolumn{1}{c}{ Category } & $\mathrm{n}(\%)$ \\
\hline Age (years) & $\geq 45$ & $32(80.0)$ \\
Sex & $<45$ & $8(20.0)$ \\
& Male & $14(35.0)$ \\
Histology type & Female & $26(65.0)$ \\
& Papillary thyroid & $29(72.5)$ \\
& carcinoma & \\
& Follicular thyroid & $11(27.5)$ \\
Lymph node metastases & carcinoma & \\
& Positive & $32(80.0)$ \\
& Negative & $8(20.0)$ \\
\hline
\end{tabular}

Flow cytometric analysis of Th17, Tc17 and Treg cells. In the present study $\mathrm{CD} 3^{+} \mathrm{CD} 8^{-} \mathrm{IL} 17^{+} \mathrm{T}$ cells were identified as Th17 cells, $\mathrm{CD}^{+}{ }^{+} \mathrm{CD} 8^{+} \mathrm{IL} 17^{+} \mathrm{T}$ cells as $\mathrm{Tc} 17$ cells and $\mathrm{CD}^{+}{ }^{+} \mathrm{CD} 25^{+} \mathrm{Foxp}^{+} \mathrm{T}$ cells as Treg cells. The intracellular cytokine levels were assessed by flow cytometry to identify the cytokine-producing cells, as previously described (13). Briefly, PBMCs $\left(2 \times 10^{7}\right)$ were stimulated with phorbol myristate acetate $(25 \mathrm{ng} / \mathrm{ml})$, monensin $(1.7 \mu \mathrm{g} / \mathrm{ml})$ and ionomycin $(1 \mu \mathrm{g} / \mathrm{ml}$; all were purchased from Alexis Biochemicals; Enzo Life Sciences, Inc., Farmingdale, NY, USA). The cells were incubated with anti-CD3-phycoerythrin (PE)-Cy5 $(0.6 \mu \mathrm{g} / \mathrm{ml}, 15-0038-42$, eBioscience; Thermo Fisher Scientific, Inc., Waltham,, MA, USA) and anti-CD8-fluoresciene isothiocyanate (FITC) $(5 \mu \mathrm{g} / \mathrm{ml}$, MHCD0801, eBioscience; Thermo Fisher Scientific, Inc.) monoclonal antibodies at room temperature in the dark for $15 \mathrm{~min}$. Following fixation with $4 \%$ paraformaldehyde (Sigma-Aldrich; Merck KGaA) and permeabilization with $1 \%$ saponin (Sigma-Aldrich; Merck $\mathrm{KGaA}$ ) for $15 \mathrm{~min}$ at room temperature, cells were stained anti-IL17-PE monoclonal antibody $(2.5 \mu \mathrm{g} / \mathrm{ml}, 12-7517-42$, eBioscience; Thermo Fisher Scientific, Inc.) at room temperature in the dark for $15 \mathrm{~min}$. Similarly, the culture supernatant was incubated with a mixture of anti-CD4-FITC monoclonal antibody $(2.5 \mu \mathrm{g} / \mathrm{ml}, 11-0048-42$, eBioscience; Thermo Fisher Scientific, Inc.) and anti-CD25-allophycocyanin (APC) monoclonal antibody $(0.6 \mu \mathrm{g} / \mathrm{ml}, 17-0257-42$, eBioscience; Thermo Fisher Scientific, Inc.) at $4^{\circ} \mathrm{C}$ in the dark for $30 \mathrm{~min}$. Following fixation and permeabilization, the cells were stained with anti-Foxp3-PE monoclonal antibody $(2.5 \mu \mathrm{g} / \mathrm{ml}, 12-4776-42$ eBioscience; Thermo Fisher Scientific, Inc.) at $4^{\circ} \mathrm{C}$ in the dark for $45 \mathrm{~min}$. Flow cytometric analysis was performed using a FACSCalibur (BD Biosciences, Franklin Lakes, NJ, USA). Data were analyzed with the BD FACSDiva software (version 6.0, BD Biosciences) (13).

ELISA. Serum was used to determine cytokine levels, including IL-10 (F01360), IL-17 (F01450), IL-23 (F01534) and TGF- $\beta$ (F02750), with a quantitative sandwich-enzyme immunoassay technique, according to the manufacturer's instructions (Westang; Biotech Co., Ltd., Shanghai, China). All samples were measured in duplicate. 
A

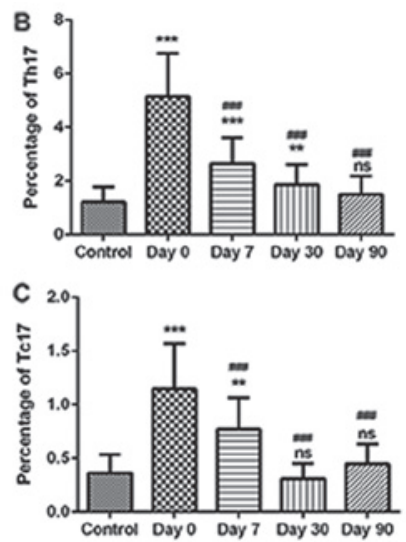

E

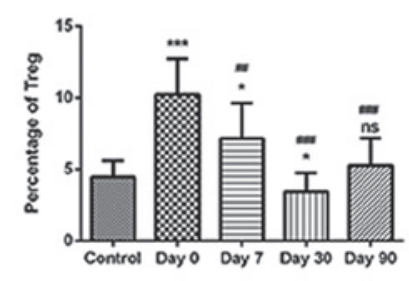

Figure 1. Percentages of Th17, Tc17 and Treg cells in healthy Control subjects and in patients with DTC. Levels of Th17, Tc17 and Treg cells were examined prior to 131I therapy (day 0) and at 7,30 and 90 days post-therapy. (A) Frequency of Th17 and Tc17 cells were detected by flow cytometry. (B) The proportion of Th17 cells in Control patients and in patients with DTC following ${ }^{131} \mathrm{I}$ therapy. (C) Proportion of Tc17 cells. (D) Frequency of Treg cells. (E) Proportion of Treg cells. ${ }^{*} \mathrm{P}<0.05,{ }^{* *} \mathrm{P}<0.01$ and ${ }^{* * *} \mathrm{P}<0.001$ vs. Control group; ${ }^{\# \#} \mathrm{P}<0.01$ and ${ }^{\# \#} \mathrm{P}<0.001$ vs. Day $0 .{ }^{131}$ I, radioactive iodine-131; DTC, differentiated thyroid cancer; Tc, T cytotoxic cell; Th, T helper cell; Treg, regulatory T cell; ns, not significant.

Statistical analysis. Data are expressed as the mean \pm standard deviation and median values. Differences between groups were determined using one-way analysis of the variance, followed by the Tukey's test. Correlation analysis was evaluated by Pearson's correlation test. All tests were performed using SPSS 13.0 (SPSS, Inc., Chicago, IL, USA). P<0.05 was considered to indicate a statistically significant difference.

\section{Results}

Frequencies of Th17 and Tc17 cells in DTC patients preand post- ${ }^{131}$ I therapy. The frequency of Th17 and Tc17 cells in the peripheral blood samples from 13 Control subjects and 40 patients with DTC who had total thyroidectomy were analyzed by flow cytometry prior to and following ${ }^{131} \mathrm{I}$ therapy. The percentage of Th17 and Tc17 cells was significantly increased in patients with DTC at day 0 compared with those in the Control group (Fig. 1A-C). At days 7, 30 and 90 following ${ }^{131}$ I therapy, the percentage of Th17 and Tc17 cells significantly decreased compared with the levels at day 0 ; in addition, at 90 days following ${ }^{131} \mathrm{I}$ therapy, no significant difference in the percentage of Th17 and Tc17 cells was detected between patients with DTC and healthy subjects (Fig. 1A-C).

Treg cell frequency in patients with DTC pre- and post- ${ }^{131}-I$ therapy. At day 0, the percentage of Treg cells was significantly increased in patients with DTC compared with Control group
(Fig. 1D and E). At 7, 30 and 90 days following therapy, the percentage of Treg cells was significantly decreased compared with treated patients at day 0 ; at 90 days post-therapy, no significant difference in the percentage of Treg cells was indicated between patients with DTC and healthy Control subjects (Fig. 1D and E).

Serum concentrations of IL-17, IL-23, IL-10 and TGF- $\beta 1$ in patients with DTC pre-and post ${ }^{131} I$ therapy. Serum levels of IL-17, IL-23, IL-10 and TGF- $\beta 1$ were measured by ELISA. IL-17 and IL-23 levels were significantly increased in patients with DTC at day 0 compared with the levels in the healthy Control patients (Fig. 2A and B), which was consistent with the elevated prevalence of Th17 and Tc17 cells in these patients. Subsequently, at 7, 30 and 90 days following ${ }^{131} \mathrm{I}$ therapy, IL-17 and IL-23 levels were significantly decreased; no significant difference was indicated for the expression levels of IL-17 and IL-23 in patients with DTC 90 days post-therapy compared with healthy subjects (Fig. 2A and B). Similarly, the serum levels of IL-10 and TGF- $\beta 1$ were significantly increased in patients with DTC at day 0 compared with the Control patients (Fig. 2C and D), which was consistent with the elevated prevalence of Treg cells in these patients. At days 7, 30 and 90 post-therapy, IL-10 and TGF- $\beta 1$ levels were significantly decreased, and no significant difference was indicated for the levels of IL-10 and TGF- $\beta 1$ in patients with DTC at 90 days compared with healthy patients (Fig. 2C and D). 
A

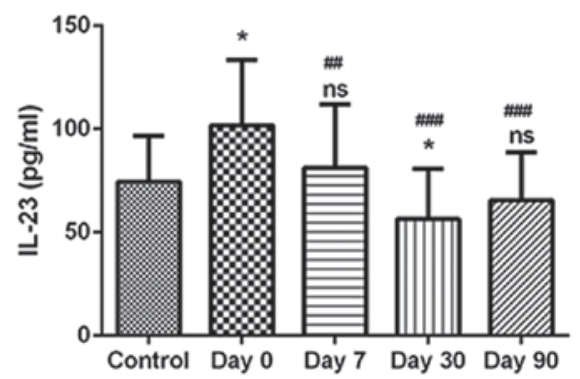

C

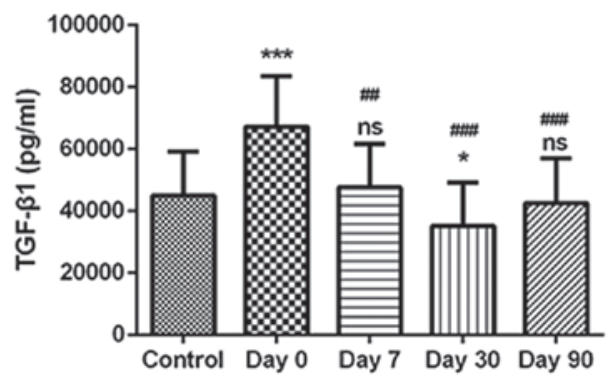

B

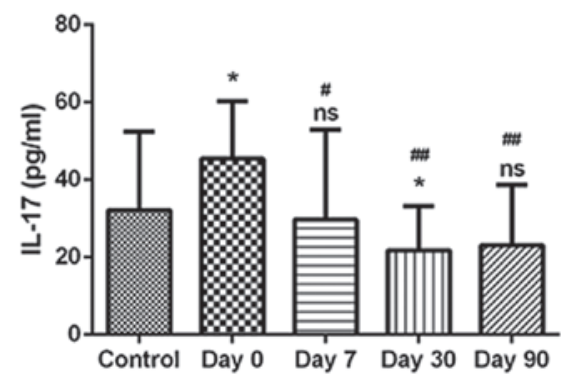

D

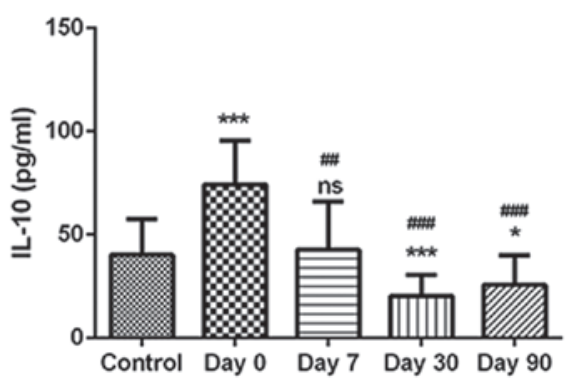

Figure 2. Concentration levels of IL-23, IL-17, TGF- $\beta 1$ and IL-10 in healthy patients and in patients with DTC. The concentration levels of (A) IL-23, (B) IL-17, (C) TGF- $\beta 1$ and (D) IL-10 were measured by ELISA in serum from Control subjects and in patients with DTC prior to and 7, 30 and 90 days following ${ }^{131}$ I therapy. " $\mathrm{P}<0.05$ and ${ }^{* * * *} \mathrm{P}<0.001$ vs. Control group; ${ }^{*} \mathrm{P}<0.05$, ${ }^{\# \#} \mathrm{P}<0.01$ and ${ }^{\# \# \#} \mathrm{P}<0.001$ vs. Day $0 .{ }^{131}$ I, radioactive iodine-131; DTC, differentiated thyroid cancer; IL, interleukin, TGF- $\beta 1$, transforming growth factor- $\beta 1$; ns, not significant.
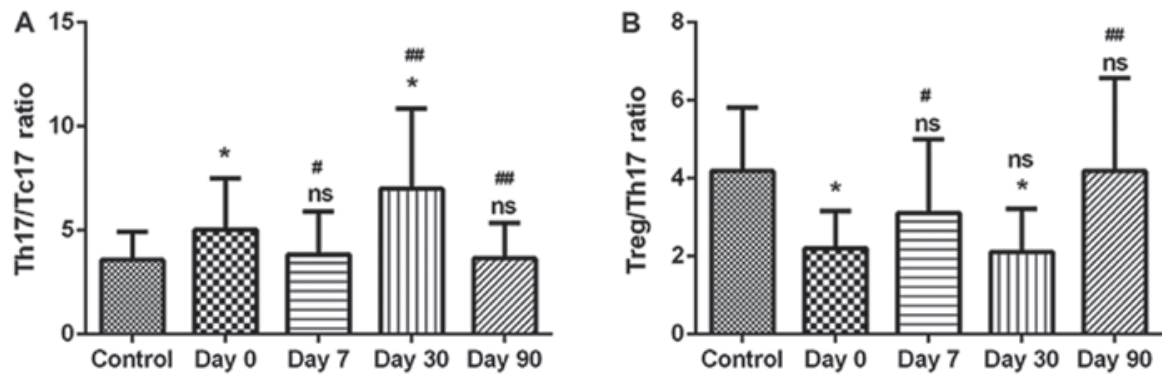

Figure 3. Ratios of Th17/Tc17 and Tg17/Treg in healthy patients and patients with DTC. The ratios of (A) Th17/Tc17 and (B) Treg/Th17 were measured in healthy Control patients and in patients with DTC prior to and 7, 30 and 90 days following ${ }^{131} \mathrm{I}$ therapy. ${ }^{*} \mathrm{P}<0.05$ vs. Control group; ${ }^{\prime \prime} \mathrm{P}<0.05$ and ${ }^{\# \prime} \mathrm{P}<0.01$ vs. Day 0; ns, not significant. ${ }^{131} \mathrm{I}$, radioactive iodine-131; DTC, differentiated thyroid cancer; Tc, T cytotoxic cell; Th, T helper cell; Treg, regulatory T cell; ns, not significant.

Balances between Th17/Tc17 and Treg/Th17 cells pre- and post ${ }^{131}$ I therapy. Compared with the Controls, the Th17/Tc17 ratio was significantly elevated in patients with DTC at day 0 (Fig. 3A). Furthermore, this ratio in patients with DTC was reduced following ${ }^{131} \mathrm{I}$ therapy for 7 days. Subsequently, this ratio was unexpectedly increased after ${ }^{131} \mathrm{I}$ therapy for 30 days. Additionally, the Th17/Tc17 ratio was not significantly different from the Control group at 90 days following ${ }^{131}$ I therapy (Fig. 3A). It is possible that ${ }^{131} \mathrm{I}$ also resulted in radioactive damage to DTC patients. Conversely, the Treg/Th17 ratio was significantly decreased in patients with DTC compared with the Controls, and this ratio in patients with DTC was elevated following ${ }^{131} \mathrm{I}$ therapy for 7 days. Subsequently, at 30 days post-therapy, this ratio was decreased. Furthermore, no significant difference was indicated in the Treg/Th17 ratio between patients with DTC and the healthy Controls following ${ }^{131}$ I therapy for 90 days (Fig. 3B). In addition, a strong positive correlation between Th17 and Tc17 cell levels was observed in the healthy Controls and in the DTC patients that received ${ }^{131}$ I treatment for 90 days (Fig. 4A); while a weak positive correlation between Th17 and Treg cell levels was identified in the healthy Controls and no obvious correlation between Th17 and Treg cells was observed in patients with DTC pre- and post- ${ }^{-13} \mathrm{I}$ therapy during the entire treatment period (Fig. 4B).

\section{Discussion}

A number of previous studies have demonstrated that inflammation orchestrates the tumor microenvironment. For example, inflammatory reactions in the tumor microenvironment were reported to be key components of tumor-associated immunity (23), in which immune cells serve crucial roles. Th17, Tc17 and Treg cells are three representative types of 

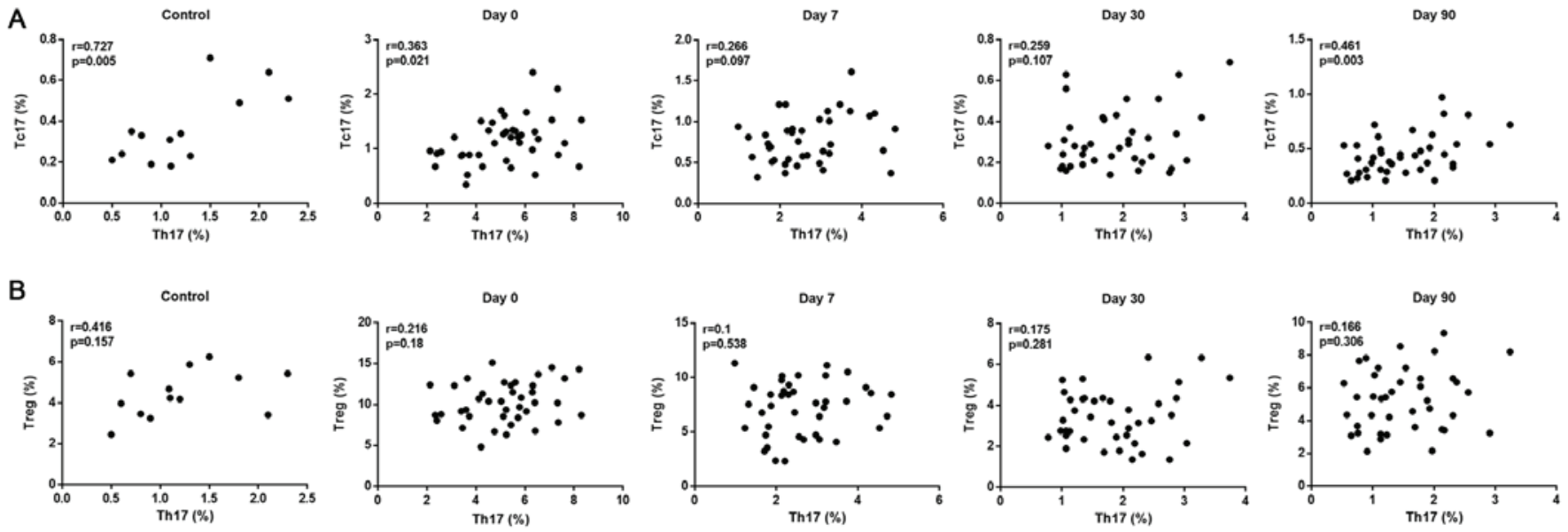

Figure 4. Correlations among Th17, Tc17 and Treg frequencies were determined by Pearson's correlation test. (A and B) Correlation between the levels of (A) Th17 and Tc17 cells (B) Treg and Th17 cells in healthy Controls and patients with DTC prior to and 7,30 and 90 days following ${ }^{131}$ I therapy. ${ }^{131}$ I, radioactive iodine-131; DTC, differentiated thyroid cancer; Tc, T cytotoxic cell; Th, T helper cell; Treg, regulatory T cell.

immune cells that are important in antitumor immunity and inflammation $(19,22,24)$. Additionally, it was reported that higher levels of Treg cells are associated with poor survival (25). These findings suggested the probable involvement of these three cells in the development of DTC. In the present study, a significant increase in the levels of Th17, Tc17 and Treg cells was observed in patients with DTC; these results were similar to those observed in endometrial carcinoma (13), which suggested that these three effector T cells may serve important roles in the progression of DTC.

Th17 and Tc17 cells have obtained an increasing amount of attention owing to their roles in tumorigenesis; their levels, as well as IL-17 production, are upregulated in the peripheral blood of patients with cancer $(19,26,27)$. Similarly, results from the present study revealed significant increases in the number of Th17 and Tc17 cells in the peripheral blood of patients with DTC. In addition, a strong positive correlation was identified between Th17 and Tc17 cells, and the Th17/Tc17 ratio was significantly elevated in patients with DTC, which suggests that the increase in Th17 cells may exceed that of Tc17 cells. In addition, an elevated proportion of Treg cells, and an imbalance between Treg and Th17 cells in patients with DTC were also observed. Treg cells are known to inhibit host immunity (28); it was reported that higher levels of Treg cells is associated with poor survival (25). Increased Treg frequency may result in tolerance of tumor cells from the host and may aid DTC cell survival and migration. In the present study, the Treg/Th17 ratio was significantly decreased in patients with DTC, and the positive correlation between Th17 and Treg cells observed in healthy Controls disappeared in patients with DTC. Similar results have been demonstrated in patients with cervical cancer and prostate cancer $(21,26)$. The present study hypothesized that Th17 and Treg cell levels increased owing to immune reactions in the tumor microenvironment. Results suggested that the number of Th17 cells produced was greater compared with the number of Treg cells. Although cytokine concentrations have been previously analyzed in patients with different cancers (29-31), they have seldom been examined in patients with DTCs. Results from the present study also demonstrated that levels of cytokines IL-17, IL-23, IL-10 and
TGF- $\beta 1$ levels were significantly elevated in patients with DTC.

However, alterations of Th17, Tc17, Treg cell levels and related cytokine secretion in patients with DTC that were treated with ${ }^{131}$ I are not distinct. It has been reported previously that iodine-125 stimulates the antitumor immune response by facilitating Th2/Th1 deviation in patients with hepatocellular carcinoma (32). In addition, the proportions of Treg, IL-10 and TGF- $\beta$ levels were significantly reduced in patients with Graves disease, some of which recovered following ${ }^{131} \mathrm{I}$ treatment (33). It has also been reported that Th2 cytokine levels, including IL-4, IL-6 and IL-10, were reduced in patients with DTC following ${ }^{131} \mathrm{I}$ therapy (11). Another previous study reported that the IL-23/Th17 axis may serve a key role in the pathogenesis of Graves disease, and the levels of serum IL-17 and IL-23 were demonstrated to gradually decrease following treatment with ${ }^{131}$ I (34). Results from the present study indicated a significant decrease in the number of Th17, Tc17, Treg cells as well as in the production of related cytokines, including IL-17, IL-23, IL-10 and TGF- $\beta 1$, in patients with DTC following ${ }^{131}$ I therapy; these results differed from those reported by Jing et al (33), perhaps owing to the differences in the number and type of inflammatory cells associated with DTC and Graves disease. In addition, the ratio of Th17/Tc17 was significantly elevated in patients with DTC at day 0 and this ratio fluctuated significantly following ${ }^{131} \mathrm{I}$ therapy, but it returned to the similar levels detected in healthy Controls 90 days post- ${ }^{-131}$ I therapy. Meanwhile, Treg/Th17 ratio was significantly reduced in patients with DTC at day 0 and this ratio also fluctuated significantly following ${ }^{131} \mathrm{I}$ therapy, but it finally returned to the similar levels detected in healthy Controls 90 days post $-{ }^{131}$ I therapy. These results indicated that ${ }^{131}$ I may influence the balance of Th17/Tc17 and Treg/Th17 in patients with DTC.

In conclusion, the numbers of Th17, Tc17 and Treg cells, as well as the levels of related cytokines (IL-17, IL-23, IL-10 and TGF- $\beta 1$ ) were significantly increased in patients with DTCs; however, at 90 days following ${ }^{131} \mathrm{I}$ therapy, the levels decreased and returned to the similar values as detected in healthy Control patients. These data suggested that ${ }^{131} \mathrm{I}$ may influence the balance of Th17/Tc17 and Treg/Th17 in patients with DTC. 
Further studies are required to determine the significance of these findings.

\section{References}

1. Burgess JR and Tucker P: Incidence trends for papillary thyroid carcinoma and their correlation with thyroid surgery and thyroid fine-needle aspirate cytology. Thyroid 16: 47-53, 2006.

2. Davies L and Welch HG: Increasing incidence of thyroid cancer in the United States, 1973-2002. JAMA 295: 2164-2167, 2006.

3. Wu X, Groves FD, Mclaughlin CC, Jemal A, Martin J and Chen VW: Cancer incidence patterns among adolescents and young adults in the United States. Cancer Causes Control 16 309-320, 2005.

4. Sherman SI: Thyroid carcinoma. Lancet 361: 501-511, 2003.

5. Coleman MP, Babb P, Damiecki P, Grosclaude P, Honjo S, Jones J, Knerer G, Pitard A, Quinn MJ, Sloggett A and De Stavola BL: Cancer survival trends in England and Wales, 1971-1995: deprivation and NHS Region. Studies in Medical and Population Subjects no. 61. The Stationery Office, London, 1999.

6. Schlumberger M and Sherman SI: Approach to the patient with advanced differentiated thyroid cancer. Eur J Endocrinol 166 $5-11,2012$

7. American Thyroid Association (ATA) Guidelines Taskforce on Thyroid Nodules and Differentiated Thyroid Cancer; Cooper DS Doherty GM, Haugen BR, Hauger BR, Kloos RT, Lee SL, Mandel SJ, Mazzaferri EL, McIver B, et al: Revised American Thyroid Association management guidelines for patients with thyroid nodules and differentiated thyroid cancer. Thyroid 9: $1167-1214,2009$.

8. Luster M, Clarke SE, Dietlein M, Lassmann M, Lind P, Oyen WJ, Tennvall J and Bombardieri E; European Association of Nuclear Medicine (EANM): Guidelines for radioiodine therapy of differentiated thyroid cancer. Eur J Nucl Med Mol Imaging 35: 1941-1159, 2008

9. Bodelon C, Polley MY, Kemp TJ, Pesatori AC, Mcshane LM, Caporaso NE, Hildesheim A, Pinto LA and Landi MT: Circulating levels of immune and inflammatory markers and long versus short survival in early-stage lung cancer. Ann Oncol 24: 2073-2079, 2013.

10. Budhu A and Xin WW: The role of cytokines in hepatocellular carcinoma. J Leukoc Biol 80: 1197-1213, 2006.

11. Simonovic SZ, Mihaljevic O, Majstorovic I, Djurdjevic P, Kostic I, Djordjevic OM and Teodorovic LM: Cytokine production in peripheral blood cells of patients with differentiated thyroid cancer: Elevated Th2/Th9 cytokine production before and reduced $\mathrm{Th} 2$ cytokine production after radioactive iodine therapy. Cancer Immunol Immunother 64: 75-82, 2015.

12. Pluijmen MJ, Eustatia-Rutten C, Goslings BM, Stokkel MP, Arias AM, Diamant M, Romijn JA and Smit JW: Effects of low-iodide diet on postsurgical radioiodide ablation therapy in patients with differentiated thyroid carcinoma. Clin Endocrinol (Oxf) 58: 428-435, 2003.

13. Zhang W, Hou F, Zhang Y, Tian Y, Jiao J, Ma D, Kong B and Cui B: Changes of Th17/Tc17 and Treg/Th17 cells in endometrial carcinoma. Gynecol Oncol 132: 599-605, 2014

14. Bailey SR, Nelson MH, Himes RA, Li Z, Mehrotra S and Paulos CM: Th17 cells in cancer: The ultimate identity crisis. Front Immunol 5: 276, 2014.

15. Carvalho DFG, Zanetti BR, Miranda L, Hassumi-Fukasawa MK, Miranda-Camargo F, Crispim JCO and Soares EG: High IL-17 expression is associated with an unfavorable prognosis in thyroid cancer. Oncol Lett 13: 1925-1931, 2017.

16. Henriques A, Inês L, Couto M, Pedreiro S, Santos C, Magalhães M, Santos P, Velada I, Almeida A, Carvalheiro T, et al: Frequency and functional activity of Th17, Tc17 and other T-cell subsets in Systemic Lupus Erythematosus. Cell Immunol 264: 97-103, 2010.
17. Garcia-Hernandez Mde L, Hamada H, Reome JB, Misra SK, Tighe MP and Dutton RW: Adoptive transfer of tumor-specific Tc17 effector T cells controls the growth of B16 melanoma in mice. J Immunol 184: 4215-4227, 2010.

18. Zou W: Regulatory T cells, tumour immunity and immunotherapy. Nat Rev Immunol 6: 295-307, 2006.

19. Maruyama T, Kono K, Mizukami Y, Kawaguchi Y, Mimura K, Watanabe M, Izawa S and Fujii H: Distribution of Th17 cells and FoxP3(+) regulatory $\mathrm{T}$ cells in tumor-infiltrating lymphocytes, tumor-draining lymph nodes and peripheral blood lymphocytes in patients with gastric cancer. Cancer Sci 101: 1947-1954, 2010.

20. Gerloni M and Zanetti M: CD4 T cells in tumor immunity. Springer Seminars Immunopathol 27: 37-48, 2005.

21. Sfanos KS, Bruno TC, Maris CH, Xu L, Thoburn CJ, DeMarzo AM, Meeker AK, Isaacs WB and Drake CG: Phenotypic analysis of prostate-infiltrating lymphocytes reveals Th17 and treg skewing. Clin Cancer Res 14: 3254-3261, 2008.

22. Korn T, Bettelli E, Oukka M and Kuchroo VK: IL-17 and Th17 cells. Annu Rev Immunol 27: 485-517, 2009.

23. Zou W and Restifo NP: T(H)17 cells in tumour immunity and immunotherapy. Nat Rev Immunol 10: 248-256, 2010.

24. Dubin PJ and Kolls JK: Th17 cytokines and mucosal immunity. Immunol Rev 226: 160-171, 2008.

25. Fattorossi A, Battaglia A, Ferrandina G, Buzzonetti A, Legge F, Salutari V and Scambia G: Lymphocyte composition of tumor draining lymph nodes from cervical and endometrial cancer patients. Gynecol Oncol 92: 106-115, 2004.

26. Zhang Y, Ma D, Tian Y, Wang X, Qiao Y and Cui B: The imbalance of Treg/Th17 in patients with uterine cervical cancer. Clin Chim Acta 412: 894-900, 2011

27. Rogala E, Nowicka A, Bednarek W, Barczyński B, Wertel I, Zakrzewski $\mathrm{M}$ and Kotarski J: Evaluation of the intracellular expression of interleukin 17 in patients with ovarian cancer. Ginekol Pol 83: 424-428, 2012 (In Polish)

28. Wang RF: Regulatory $\mathrm{T}$ cells and innate immune regulation in tumor immunity. Springer Semin Immunopathol 28: 17-23, 2006.

29. Baier PK, Wolff-Vorbeck G, Eggstein S, Baumgartner U and Hopt UT: Cytokine expression in colon carcinoma. Anticancer Res 25: 2135-2139, 2005.

30. Montero AJ, Diaz-Montero CM, Millikan RE, Liu J, Do KA, Hodges S, Jonasch E, McIntyre BW, Hwu P and Tannir N: Cytokines and angiogenic factors in patients with metastatic renal cell carcinoma treated with interferon-alpha: Association of pretreatment serum levels with survival. Ann Oncol 20: 1682-1687, 2009

31. Mocellin S, Provenzano M, Rossi CR, Pilati P, Nitti D and Lise M: Use of quantitative real-time PCR to determine immune cell density and cytokine gene profile in the tumor microenvironment. J Immunol Methods 280: 1-11, 2003.

32. Xiang GA, Chen KY, Wang HN and Xiao JF: Immunological influence of iodine-125 implantation in patients with hepatocellular carcinoma resection. Nan Fang Yi Ke Da Xue Xue Bao 30: 292-294, 2010.

33. Yang J, Pan T, Du YJ and Zhong X: Endocrinology Do. Change of $\mathrm{CD} 4+\mathrm{CD} 25+\mathrm{CD} 127$ low regulatory T cells in peripheral blood of patients with Graves disease treated by 131 I or antithyroid drugs therapy. J Anhui Medicinalis 5: 691-695 2016.

34. Xue-Qin MA and Shi-Peng YU: Effects of ${ }^{131}$ I treatment on the IL-23/Th17 axis relevant factor levels in graves disease patients. Chin J Immunol 29: R392, 2013 